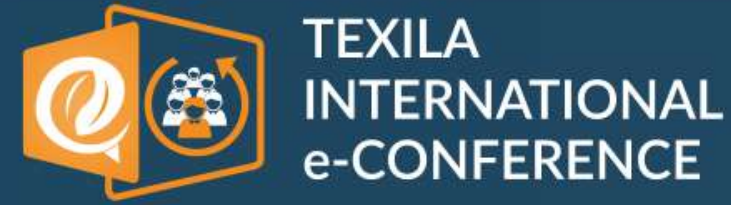

$$
\text { ISSN: 2518-8852 }
$$

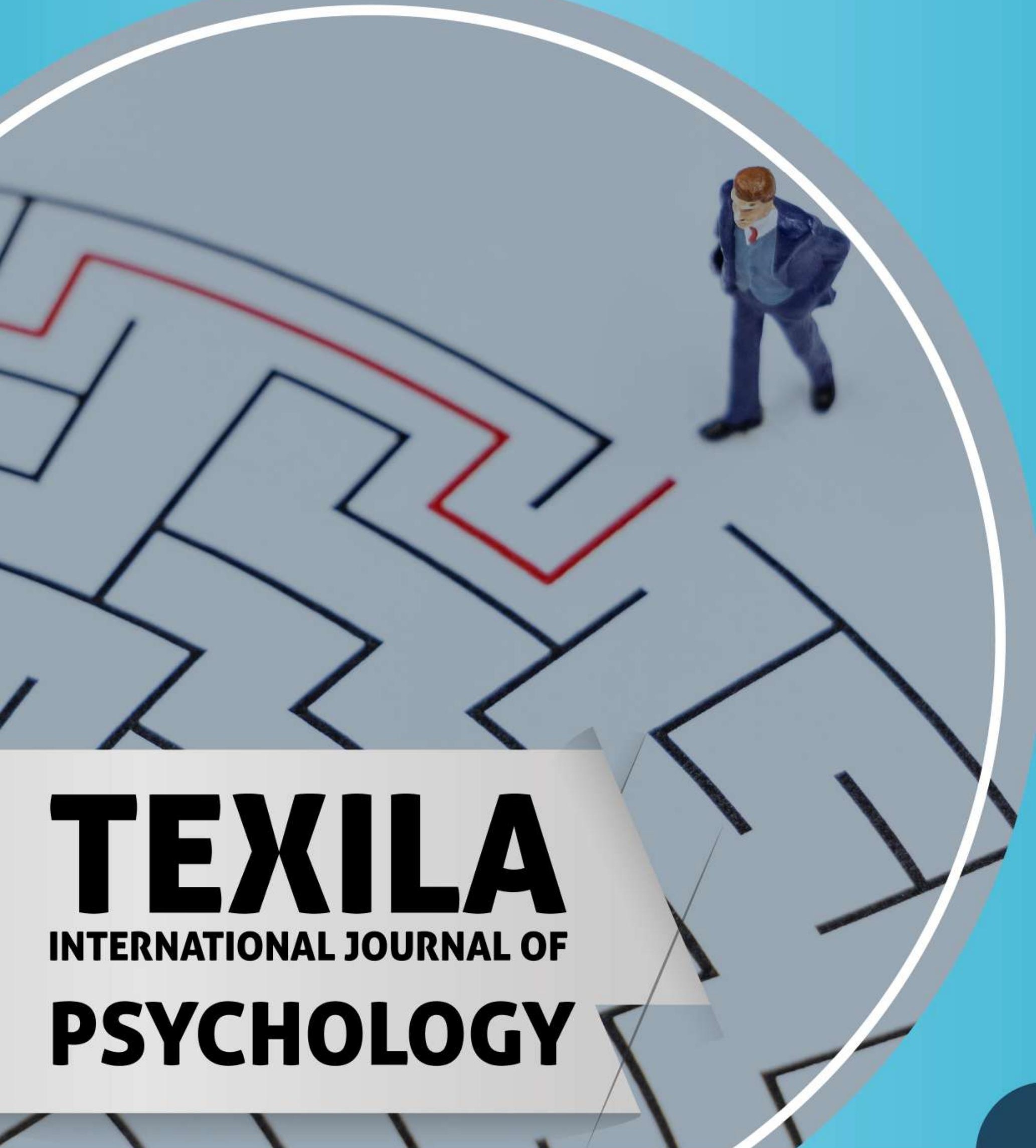




\section{EDITORIAL POLICY}

Papers must be submitted with the understanding that they have not been published elsewhere (except in the form of an abstract or as part of a published lecture, review, or thesis) and are not currently under consideration by another journal published or any other publisher. The submitting (Corresponding) author is responsible for ensuring that the article's publication has been approved by all the other coauthors. It is also the authors' responsibility to ensure that the articles coming from a particular institution are submitted with the approval of the necessary institution. Only an acknowledgment from the editorial office officially establishes the date of receipt. It is a condition for submission of a paper that the authors permit editing of the paper for readability. All enquiries concerning the publication of accepted papers should be addressed to ejournal.assist @ tau.edu.gy.

\section{PEER REVIEWER}

Dr. S.T. Janetius, Professor of Psychology, PG Department of Psychology, Jain University. 


\section{ABOUT PLAGIARISM}

Plagiarism is the use or close imitation of the language and ideas of another author and representation of them as one's own original work. Duplicate publication, sometimes called self plagiarism, occurs when an author reuses substantial parts of his or her own published work without providing the appropriate references. This can range from getting an identical paper published in multiple journals, where authors add small amounts of new data to a previous paper.

Plagiarism can be said to have clearly occurred when large chunks of text have been cut and pasted. Such manuscripts would not be considered for publication in TIJBMS Journal. But minor plagiarism without dishonest intent is relatively frequent, for example when an author reuses parts of an introduction from an earlier paper. The editors will judge any case of which they become aware (either by their own knowledge of and reading about the literature, or when alerted by referees) on its own merits.

The paper containing the plagiarism will be obviously returned back to the author's for review, but we earnestly request the authors to avoid submitting plagiarized. 


\section{DISCLAIMER}

Texila International Journal of Psychology (TIJP) make every effort to ensure the accuracy of all the information (the "Content") contained in its publications. However, the TIJP and its agents make no representations or warranties whatsoever as to the accuracy, completeness or suitability for any purpose of the Content and disclaim all such representations and warranties whether express or implied to the maximum extent permitted by law. Any views expressed in this publication are the views of the authors and are not necessarily the views of the Editor's or Texila International Journal of Psychology. 


\title{
Personality Traits, Anxiety and Depression as Predictors of Quality of Life among Breast Cancer Patients in Uch, Ibadan
}

\author{
Article by Johnson T. Oyeleke, Onyinye Jason \\ ${ }^{1}$ PhD., Department of Psychology, University of Ilorin, Nigeria \\ ${ }^{2}$ Bsc, Department of Psychology, Nigeria \\ E-mail: oyelekejohnson@gmail.com ${ }^{1}$,onyinye.jason@yahoo.com ${ }^{2}$
}

\begin{abstract}
This study investigated personality traits, anxiety and depression as predictors of quality of life among breast cancer patients in UCH, Ibadan. Quality of life (QoL) is an important outcome measurement when evaluating the results of cancer treatment. It is a multidimensional concept that measures the satisfaction of a person with a wide range of aspects.

The study made use of cross-sectional design. 247 participants took part in the study. Two hypotheses generated and tested with appropriate inferential statistical tools and results are presented.

Results indicated that, personality factors (extraversion, agreeableness, openness, neuroticism and conscientiousness) jointly predicted quality of life among breast cancer patients in UCH, Ibadan at $\left\{R=.265 ; R^{2}=.070 ; F(5,241)=3.630 ; p<.05\right\}$. However, the result of the independent prediction indicates that extraversion, conscientiousness and agreeableness have significant independent influence on quality of life among breast cancer patients in UCH, Ibadan at ( $p<.05)$ while openness and neuroticism did not produce significant independent influence on quality of life ( $p>.05)$. Also, the result shows that anxiety and depression jointly and independently predicted quality of life among breast cancer patients in UCH, Ibadan at $\left\{R=.976 ; R^{2}=.953 ; F(2,244)=2451.96 ; p<.01\right\}$.

Personality traits, anxiety and depression are significant predictors of quality of life among breast cancer patients. Introduction of psycho-therapy and counselling psychology would help ameliorate the psychopathological symptoms of cancer patients. However, there is need for collaborative partnership between the primary physicians and clinical psychologists in order to achieve high treatment prognosis.
\end{abstract}

\section{Background of the study}

Breast cancer is the predominant form of malignancy in women in the developed and developing countries though in Western Europe and the United States have the most prevalence rate of this breast cancer. In Nigeria, substantial number of women develop invasive breast cancer. Greenler, Murray, Bolden \& Wingo (2000). Early detection by screening programs and improvements in chemotherapy resulted in increasing incidence and prevalence figures; so, breast cancer has become not only a life threatening cancer but also a chronic disease for many patients. Theofilou (2011) proposed that it is important to assess health - related quality of life among women undergoing cancer treatment in every community.

Quality of life $(\mathrm{QoL})$ is an important outcome measurement when evaluating the results of cancer treatment. It is a multidimensional concept that measures the satisfaction of a person with a wide range of aspects. QoL has been studied extensively in breast cancer patients, and the influence of surgical treatment on QoL has not been addressed fully. It is known that quality of life is influenced by health perception, anxiety, depression, culture, socioeconomic status, and personality (Theofilou, 2010).

The World Health Organization tried to embrace the complexity of the term "Quality of Life", defining it as "the perception that an individual has as about their place in their own existence, in the context of culture and their value system in which they live and on relation to their objectives, their expectations, their norms and life concerns. This is a very broad concept which is influenced by complex ways and complex issues than physical health of the individual factors, his psychological state, level of independence, their social relationships and their relationship with the environment" (World Health Organization [WHO], 2009).

Quality of life is a complex concept that encompasses objective and subjective dimensions such as food, housing, the opportunity to study, health and perceptions about them (Carpio, Pachecho, Flores \& Canales, 2000; Novoa, Cruz, Rojas, Wilde, 2003). Diener (1984, cited by Rodriguez, 1998) has 
defined quality of life as a subjective view of the extent to which happiness and satisfaction have been achieved, or as a sense of personal, subjective view that has also been considered closely related to certain biological, economic, psychological and social factors (Garavito, 2001; Gomez Villegas de Posada, Barrera \& Cruz, 2007).

Personality is the primary psychological factor defined as an individual's unique and enduring traits which influence his/her way of thinking, feeling and behaving. Goodwin et al (2002) published a research work on personality and the perception of health. Over the years, a number of theories that attempt to describe the key traits of human being among what is known as the five personality factors or better still called "the Big five" Goldberg, (1990) still emphasize this big-five personality factors as including extraversion, agreeableness, conscientiousness, neuroticism and openness to experience.

The five-factor structure has generalized across cultures and rating formats (self, peer, observer, and stranger ratings), and there is considerable evidence that the Big Five are heritable and stable over time (Costa \& McCrae, 1992). The factors comprising the Big Five are:(1) extraversion, which represents the tendency to be sociable, assertive, expressive, and active; (2) agreeableness, representing the tendency to be likable, nurturing, adaptable, and cooperative; (3) conscientiousness, referring to the traits of achievement, organization, task-focus, and dependability; (4) Neuroticism/emotional stability, which is the tendency to be secure, emotionally adjusted and calm; and (5) openness to experience, which is the disposition to be imaginative, artistic, non-conforming, and autonomous.

State anxiety is conceptualized as a transitory emotional state or condition that is characterized by subjective, consciously perceived feelings of tension and apprehension and heightened autonomic nervous system activity. Trait anxiety refers to relatively stable individual differences in anxiety proneness that is due to differences between people in the tendency to respond to situations perceived as threatening with elevations in state anxiety intensity dribbling can psychologically affect the patients' quality of life, which can contribute to the high level of anxiety Deyo, Dichr \& Patrick, (2001). Therefore, this study will consider State-Trait anxiety as one of the psychological factors predicting quality of life among breast cancer patients.

Depression has been defined as a psychiatric disorder characterized by an inability to concentrate, insomnia, loss of appetite, anhedonia, feelings of extreme sadness, guilt, helplessness and hopelessness, and thoughts of death, Hankin \& Abramson, (2001). Depression is a pervasive and impairing illness that affects both women and men, but women experience depression at roughly twice the rate of men. On the basis of strong and consistent evidence, women appear to have higher rates of depression than do men. However, the explanation for this difference is not understood well, Wilhelm \& Roy, (2002).

Cancer treatment has improved the long-term survival of women with breast cancer; however, women continue to suffer substantial psychological distress (symptoms of depression and anxiety) during treatment that influences cancer recovery significantly and the role of individual differences on perceived quality of life cannot be over-emphasized. As a result, this study has set out to investigate personality trait, anxiety and depression as predictors of quality of life among women undergoing breast cancer treatment in Radiotherapy and Surgical out-patient Clinic in University College Hospital (UCH) Ibadan.

However, women with breast cancer routinely describe the negative consequences of the illness on themselves and on their immediate family members (Manne et al., 2003). Systems theory would predict that major events, such as a serious illness, affect the larger family and social networks, not just the ill individual (Broderick, 1993). A major event such as the diagnosis of cancer and its treatment can cause dramatic changes in relationships, roles, and psychological health for both cancer patients and their family members (Ferrell, Grant, Funk, Otis-Green, \& Garcia, 1997a, 1997b). Cancer survivors and their family members often experience anxiety, stress, depression, and uncertainty.

Depression in cancer populations is estimated from 1.5\% to 50\% (Trask, 2004), with anxiety estimates ranging from $20 \%$ to $50 \%$ (Stark et al., 2002). Depression and anxiety are correlated highly in women with breast cancer, and many women suffer from both types of symptoms. Women with substantial symptoms of depression and anxiety often experience increased physical side effects and more difficulty managing these side effects, and may experience overall reduced quality of life (QOL; Badger, Braden, Mishel, \& Longman, 2004; Giese-Davis \& Spiegel, 2003). Symptoms of depression and anxiety also decrease women's abilities to mobilize critical support when the need for it is greatest (Badger, Braden, Longman, \& Mishel, 1999; Manne et al., 2004). 
Further, the experience of negative mood states, such as depression and anxiety, significantly increases the risk of mortality in women with breast cancer (Schou, Ekeberg, Ruland, Sandvik, \& Karesen, 2004). Women with breast cancer routinely describe the negative consequences of the illness on themselves and on their immediate family members (Manne et al., 2003). Systems theory would predict that major events, such as a serious illness, affect the larger family and social networks, not just the ill individual (Broderick, 1993). A major event such as the diagnosis of cancer and its treatment can cause dramatic changes in relationships, roles, and psychological health for both cancer patients and their family members (Ferrell, Grant, Funk, Otis-Green, \& Garcia, 1997a, 1997b). Cancer survivors and their family members.

\section{Hypotheses}

1. Personality factors (extraversion, agreeableness, openness, neuroticism and conscientiousness) will have significant independent and joint influence on quality of life among women undergoing breast cancer treatment.

2. Anxiety and depression will have significant independent and joint influence on quality of life among women undergoing breast cancer treatment.

\section{Methods}

\section{Research design}

This study adopted a cross-sectional survey design. The independent variables are personality factors, anxiety and depression while the dependent variable is health related quality of life.

\section{Setting}

This study was conducted in Ibadan at the Radiotherapy and Surgical out-patient clinic in University College Hospital (UCH). The choice of this setting was based on the accessibility to a larger population sample as special to the course of the study objectives and more so UCH Ibadan is central in the treatment of breast cancer in the south-western part of Nigeria where many referral cases can be medically and adequately managed. However, the historical record showed that $\mathrm{UCH}$ was founded in 1947.

\section{Sample size determination}

At the time of this study a total number of 393 women were undergoing breast cancer treatment in radiotherapy and surgical out-patient clinic in $\mathrm{UCH}$. According to sample determination table by Krejecie \& Morgan, (1970); s= X2N (1-P) / d2 (N-1) + X2P (1-P).

$\mathrm{s}=$ Required Sample Size

$\mathrm{X} 2=$ the table value of Chi-square for 1 degree of freedom at the desired confidence level (3.841).

$\mathrm{N}=$ the population size.

$\mathrm{P}=$ the population proportion (assume to be .50 since this would provide the maximum sample size). $\mathrm{D}=$ the degree of accuracy expressed as a proportion (.05). This sample size calculation yielded 191 as the adequate sample size but oversampling was recommended by Fink, (1997), therefore the sample size used in this study was 247.

\section{Participants}

The frequency data indicate that $174(70.4 \%)$ were married, 31(12.68\%) participant were widowed/divorced, 42(17.0\%) participants were single. Duration of cancer ailment showed that $39(15.8 \%)$ participants were diagnosed for breast cancer in less than 3years, 115(46.6\%) participants were between 4 to 6 years, 7 to 9 years were 60 (24.3\%) while $33(13.4 \%)$ have been in the situation for more than 10yrs. The participants' distributions by religion showed that $145(58.7 \%)$ were Christians, 97(39.3\%) participants were Muslims while 5(2\%) participants were practicing Traditional religion. The age analysis indicates that the youngest breast cancer patient among the sample was of $19 \mathrm{yrs}$ while the oldest participant was of $77 \mathrm{yrs}$ and the mean age of the participants was $44.61, \mathrm{SD}=20.76$.

\section{Research instruments}

This study applied a standardized structured questionnaire WHICH comprise five - sections, namely A, B, C \& D; 
DOI: $10.21522 . / T I J P Y .2016 . S E .19 .01 . A r t 001$

ISSN: $2518-8852$

Section A: measures socio-demographic information of the participants, such as age, highest educational qualification, occupation, marital status and duration of cancerous condition and religion.

Section B: of the questionnaire consists of Big-five personality inventory (BFI). The scale was jointly developed by McManus \& Furnham (2006), Department of Psychology, University of California. The inventory contains 15 items measuring openness to experience $(\mathrm{r}=.67)$, conscientiousness ( $\mathrm{r}=.65)$, extraversion (.87), neuroticism (.63) and agreeableness ( $\mathrm{r}=.71)$ and it is a 5point rating scale, ranging from strongly disagree to strongly agree. Scoring: The following SPSS code should be fairly self-explanatory. Items 10, 11 and 13 are reverse scored, and the reversal is carried out by the first three statements. Score 1 for strongly disagree through 5 for strongly agree.

Neuroticism-compute (big5s $1=\mathrm{p} 3+\mathrm{p} 6+\mathrm{p} 9)$

Extraversion-compute (big5s $2=\mathrm{p} 5+\mathrm{p} 7+\mathrm{p} 8)$

Openness-compute (big5s3=p4+rp11+p14)

Agreeableness-compute (big5s $4=\mathrm{p} 1+\mathrm{rp} 10+\mathrm{p} 12)$

Conscientiousness-compute big $5 \mathrm{~s} 5=\mathrm{p} 2+\mathrm{rp} 13+\mathrm{p} 15$. The scoring procedure of this scale indicates that "the higher the score above the sample mean score on each subscale, the higher the individual on such subscale vice - versa. In this study, the reliability Cronbach's alpha for this scale is .87.

Section C: This section consists of 14 -items measuring hospital anxiety and depression (HADS) developed by Zigmong \& Snaith, (1983) each of the groups in comparison to the exploratory 2-factor PCAs. Pearson correlations between the components (subscales) in the different groups ranged from $0 \pm 43$ to $0 \pm 73$ (all significant at $P<0 \pm 001$ ), indicating that the subscales do not measure independent constructs. Data on the homogeneity of the total scale and two subscales are found reliable and valid for both clinical and social setting. In all six samples, mean inter-item correlations for HADS scales lie inside the range of $0 \pm 10$ to $0 \pm 50$ for an acceptable level of homogeneity (Nunnally, 1978). Moreover, all 14 items manifest a significant and positive correlation with the other items of the total HADS scale (range $0 \pm 20$ to $0 \pm 74$ ). Item-remainder correlations of anxiety and depression items with the other items of the anxiety and depression subscale respectively also proved to be significant and positive (range $0 \pm 21$ to $0 \pm 75$ ). Cronbach's alphas for the total scale and both subscales (range $0 \pm 71$ to $0 \pm 90$ ) are satisfactory to good (Nunnally, 1978).

Section D: of the questionnaire consists of 19-item Health related quality of life Scale (HRQLS-19). This scale was jointly developed by Nancy et al (2005). The HRQLS-19 incorporates subscales measuring negative feeling, positive feelings, cognitive problems, sexual problems, physical pain, fatigue, and social avoidance. The HRQLS-19 demonstrates satisfactory levels of internal reliability (.82), and test-retest reliability (.80). The response ranged from strongly agree, (5), Agree (4), undecided (3), disagree (2) and strongly disagree (1). The reliability for this scale in this study was found to be .77 .

\section{Procedure}

The researcher followed all the ethical guidelines in conducting this research. The UI/UCH ethical committee were approached for ethical approval. Informed consent of the respondents was obtained. The purpose, benefits and hazard of the study were explained to the participants, before the administration of the questionnaires. They were also told that they can withdraw from the study at any stage of the study and that their participating or not participating in the study has nothing to do with the treatment they are receiving in the hospital. Hence, the questionnaires were administered among the consenting participants only to ensure the voluntary nature of the study. Data collected were analysed using SPSS (statistical packages for the social sciences) version 19.0. The questionnaire administration took place at the radiotherapy and surgical out-patient clinic in UCH Ibadan. The completed questionnaires from the respondents were coded for the data analysis. Hence, of the 260 questionnaires administered on the field, only 247 was completely filled and used for the data analysis which yielded a response index of $95 \%$.

\section{Statistical analysis}

Multiple regressions analysis was used to test the hypotheses 


\section{Results}

\section{Hypothesis one}

Personality factors (extraversion, agreeableness, openness, neuroticism and conscientiousness) will have significant independent and joint influence on quality of life among women undergoing breast cancer treatment and was tested using multiple regression tests and the result is presented on table 4.1.

Table 4.1. Multiple regression analysis showing the influence of personality on quality of life

\begin{tabular}{|l|l|l|l|l|l|l|l|}
\hline Predictors & $\mathrm{R}$ & $\mathrm{R}^{2}$ & $\mathrm{~F}$ & $\mathrm{sig}$ & $\mathrm{B}$ & $\mathrm{t}$ & $\mathrm{P}$ \\
\hline Extraversion & & & & & -.176 & -2.481 & $<.05$ \\
\hline Openness' & & & & & .093 & 1.340 &.$>05$ \\
\hline Conscientiousness & 265 & .070 & 3.630 & $<.05$ & -148 & -2.082 & $<.05$ \\
\hline Neuroticism & & & & & -.088 & -1.324 & $>.05$ \\
\hline Agreeableness & & & & & .234 & 3.493 & $<.05$ \\
\hline
\end{tabular}

DV: Quality of life

Table 4.1 shows that personality traits (extraversion, openness, conscientiousness, neuroticism and agreeableness) jointly predicted quality of life among breast cancer patients at $\left\{R=.265 ; R^{2}=.070 ; F\right.$ $(5,241)=3.630 ; p<.05\}$. This implies that personality traits combined to influence the level of quality of life among breast cancer patients' by accounted for about $7 \%$ variance in the quality of life which is not due to chance factors while the remaining $93 \%$ could be attributed to other variables not considered in the hypothesis tested.

However, the result of the independent prediction indicates that extraversion, conscientiousness and agreeableness have significant independent influence on quality of life among breast cancer patients at $\mathrm{p}<.05)$ and openness and neuroticism did not produce significant independent influence on quality of life among breast cancer patients at ( $p>.05)$. Hence, the hypothesis is therefore accepted.

\section{Hypothesis two}

This states that anxiety and depression will have significant independent and joint influence on quality of life among women undergoing breast cancer treatment was tested using multiple regressions and the results are presented on table 4.2.

Table 4.2. Summary of Multiple Regressions Showing the Influence of Anxiety and Depression on Quality of life

\begin{tabular}{|l|l|l|l|l|l|l|l|}
\hline Variable & Beta & t-value & Sig & $\mathbf{R}$ & $\mathbf{R}^{\mathbf{2}}$ & $\mathbf{F}$ & $\mathbf{P}$ \\
\hline Anxiety & .520 & 15.53 & $<.01$ & & & & \\
\hline & & & & .976 & .953 & 2451.96 & $<.01$ \\
\hline Depression & .47 .9 & 14.29 & $<.01$ & & & & \\
\hline
\end{tabular}

Dependent variable: QoL

Table 4.2 above shows that anxiety and depression jointly predicted quality of life among breast cancer patients at $\left\{\mathrm{R}=.976 ; \mathrm{R}^{2}=.953 ; \mathrm{F}(2,244)=2451.96 ; \mathrm{p}<.01\right\}$. This implies that anxiety and depression jointly influenced the level of quality of life among breast cancer patients' and accounted for about $97.6 \%$ variance in the quality of life which is not due to chance factors while the remaining $2.4 \%$ could be attributed to other variables not considered in the hypothesis tested.

However, the result of the independent prediction indicates that anxiety and depression had significant independent influence on quality of life among breast cancer patients at $(\mathrm{p}<.05)$ while anxiety accounted for about $52 \%$ and depression accounted for about $48 \%$ influence on quality of life among breast cancer patients. Therefore, the hypothesis is confirmed in this study.

\section{Discussions}

Hypothesis one which states that personality factors (extraversion, agreeableness, openness, neuroticism and conscientiousness) will have significant independent and joint influence on quality of life among women undergoing breast cancer treatment was tested using multiple regression tests and the result showed that personality traits (extraversion, openness, conscientiousness, neuroticism and 
agreeableness) jointly predicted quality of life among breast cancer patients in $\mathrm{UCH}$, Ibadan. This implies that personality traits combined to influence the level of quality of life among breast cancer patients' by accounted for about $7 \%$ variance in the quality of life which is not due to chance factors while the remaining 93\% could be attributed to other variables not considered in the hypothesis tested. However, the result of the independent prediction indicates that extraversion, conscientiousness and agreeableness have significant independent influence on quality of life among breast cancer patients in $\mathrm{UCH}$, Ibadan and openness and neuroticism did not produce significant independent influence on quality of life among breast cancer patients. Hence, the hypothesis is therefore accepted.

The result is contrary to the finding of (Priestman \& Baum, 2009) suggested that the subjective quality of life was not significantly related to the patient's personality factors using big-5 personality factors (Priestman \& Baum, 2009). Diener (1984, cited by Rodriguez, 1998) has defined quality of life as a subjective view of the extent to which happiness and satisfaction have been achieved, or as a sense of personal, subjective view that has also been considered closely related to certain biological, economic, psychological and social factors (Garavito, 2001; Gomez Villegas de Posada, Barrera \& Cruz, 2007). However, personality traits such as extraversion have predicted quality of life in this study which supports the prior findings.

The World Health Organization tried to embrace the complexity of the term "Quality of Life", defining it as "the perception that an individual has as about their place in their own existence, in the context of culture and their value system in which they live and on relation to their objectives, their expectations, their norms, their concerns, etc. This is a very broad concept which is influenced by complex ways and complex issues than physical health of the individual factors, his psychological state, level of independence, their social relationships and their relationship with the environment" (World Health Organization [WHO], 2005).

Hypothesis two states that anxiety and depression will have significant independent and joint influence on quality of life among women undergoing breast cancer treatment was tested using multiple regressions and the results revealed that anxiety and depression jointly predicted quality of life among breast cancer patients. This implies that anxiety and depression jointly influenced the level of quality of life among breast cancer patients' and accounted for about $97.6 \%$ variance in the quality of life which is not due to chance factors while the remaining $2.4 \%$ could be attributed to other variables not considered in the hypothesis tested. However, the result of the independent prediction indicates that anxiety and depression had significant independent influence on quality of life among breast cancer patients, while anxiety accounted for about $52 \%$ and depression accounted for about $48 \%$ influence on quality of life among breast cancer patients. Therefore, the hypothesis is confirmed in this study.

However, this result is strongly supported by (Grimison and Stockler, 2010) found that breast cancer patients with high level of depression and anxiety also reported low level of perceived health quality of life. Health-related quality of life in patients undergoing systemic therapy for advanced breast cancer was reviewed by Bottomley and Therasse, covering the literature from 1995 to 2001. They indicated that there were 19 studies. Among these, there were 12 studies on chemotherapy, 6 hormonal trials and 1 on biological therapy (Trastuzumab). They concluded that quality of life data provided invaluable insights into the treatment and care of patients (Priestman and Baum, 2007).

Similarly, Fossati, (2010) critical review of published literature on randomized clinical trials of cytotoxic or hormonal treatments of advanced breast cancer indicated that quality of life assessments added relatively little value to classical clinical endpoints. Mols et al., (2009) reviewed the literature on quality of life among long-term survivors of breast cancer and found that although these patients experienced some specific problems such as a thick and painful arm and problems with sexual functioning, most reported good overall quality of life. The review also indicated that the current medical condition, amount of social support and current income level were strong positive predictors of quality of life, and the use of adjuvant chemotherapy emerged as a negative predictor. The authors concluded that focusing on the long-term effects of breast cancer is important when evaluating the full extent of treatment and that anxiety and depression are significant correlates of quality of life among patients with a life-threatening disease (Priestman \& Baum, 2009).

\section{Conclusion}

This study therefore concluded that personality traits, anxiety and depression are significant predictors of quality of life among breast cancer patients. Further, the demographic variables of age, 
marital status, duration of breast cancer and religion did not significantly predict quality of life among breast cancer patients receiving treatment. However, the results suggest that the level of anxiety and depression reported among the patients warrants psychological intervention for adequate management of the patient's conditions.

\section{Recommendation}

It was recommended that the cancer patients grossly suffered anxiety and depression and introducing psycho-therapist and counselling psychologist would help ameliorate the psychopathological symptoms. However, there is need for collaborative partnership between the primary physicians and clinical psychologists in order to achieve high treatment prognosis. This may include; group counselling, relaxation exercises, self-instructional therapy, cognitive behavioral therapy etc.

\section{Limitations of study}

There are several limitations to this study. Firstly, the number of patients in the study was not large enough compare the population of breast cancer patients in Nigeria, and the sample was drawn from only UCH, Ibadan. Therefore, generalization of the results needs to be carefully made. Secondly, we did not analyze the data of persons who refused to participate in the study. Therefore, certain groups of depressive patients may have been omitted. Concurrent physical co-morbidity and psychopharmacology use was not analyzed, and this may limit the generalization of the study. Finally, the study used survey research design but combining both qualitative and quantitative research methods will yield a better result with high external validity.

\section{References}

[1].Abell, N. (1991). The Index of Clinical Stress: A brief measure of subjective stress for practice and research. Social Work Research and Abstracts, 27, 12 Y15.

[2].Amir M, Ramati A. (2002) Post-traumatic symptoms, emotional distress and quality of life in long-term survivors of breast cancer: a preliminary research. Journal of Anxiety Disorder.

[3].Ariens GA, van Mechelen W, Bongers PM, et al. (2000) Physical risk factors for neck pain. Scand Journal of Work Environmental Health, 26, 7-19.

[4].Arndt V, Merx H, Sturmer T, et al. (2004) Age-specific detriments to quality of life among breast cancer patients one year after diagnosis. European Journal Cancer, 40, 673-680.

[5].Ashing-Giwa K, Ganz PA, Petersen L. (1999) Quality of life of African- American and white long-term breast carcinoma survivors.85, 418-426.

[6].Badger L, Trask E, Longman, T (2004): outpatients with depression and anxiety: worse quality of life in other chronic medical diseases in Argentina. Social sciences Med; 52:911-919.

[7].Badger, T. A. (2005). Measuring nursing-sensitive patient outcomes: Evidenced-based summary for depression. Retrieved

[8].Badger, T. A., Braden, C. J., Longman, A. J., \& Mishel, M. H. (1999). Depression burden, self-help interventions, and social support among women receiving treatment for breast cancer. Journal of Psychosocial Oncology, 17, 17Y35.

[9].Badger, T. A., Braden, C. J., Mishel, M. H., \& Longman, A. J. (2004). Depression burden, psychological adjustment and quality of life in women with breast cancer: Patterns over time. Research in Nursing \& Health, $27,19 Y 28$.

[10]. Badger, T. A., Segrin, C., Meek, P., Lopez, A. M., \& Bonham, E. (2004). A case study of telephone interpersonal counselling for women with breast cancer and their partners. Oncology Nursing Forum, 31, $997 Y 1003$.

[11]. Bandura, A. (1977). Social learning theory, Englewood Cliffs, NJ: Prentice Hall.

[12]. Barrick, M.R. \& Mount, M.K. (1991). The Big five personality dimensions and job performance: A metaanalysis personnel psychology 44, 1-26

[13]. Barsevick, A. M., Sweeney, C., Haney, E., \& Chung, E. (2002). A systematic qualitative analysis of psycho educational interventions for depression in patients with cancer. Oncology Nursing Forum, 29, 73 Y84.

[14]. Bauchaman, T, Goldberg, L. R. and Johnson, J. A. (1999). www. personality assessment: Evaluation of anon line five factor inventory. Paper presented at the 1999 meeting of the society for computers in psychology: Los Angeles $18^{\text {th }}$ Edition. 
DOI: $10.21522 . / T I J P Y .2016 . S E .19 .01 . A r t 001$

ISSN: $2518-8852$

[15]. Baucus, M. A (1994). Pressure, opportunity and predisposition; A multivariate model of corporate illegality. Journal of Management,20(4),699-721.

[16]. Bernadine, D. (1977). Personality and job dysfunction amongst salemen cited In Sarchione, C. D. Cuttler, M.J. Muchinsky, P.M. and Nelson-gray, R. (1990). Perdition of dysfunctional job behaviour among law enforcement officers Journal of applied psychology Vol83, No 6904912. Apa Inc.

[17]. Betz, M., O'Connell, L., \& Shepard, J. (1989). Gender differences in ethical work climate.

[18]. Bloom JR, Stewart SL, Chang S, et al. (2004) Then and now: quality of life of young breast cancer survivors. Psycho oncology, 13,147-160.

[19]. Borghouts JA, Koes BW, Bouter LM. (1998) The clinical course and prognostic factors of non-specific neck pain: a systematic review. Pain, 77, 1-13.

[20]. Bottomley F, (2002); Varricchio, A (2006). Psychological distress as a predictor of quality of life in men experiencing cancer: a cross-sectional survey. Cancer Journal. Health 2010b; 7:3.

[21]. Brass, D. J, Butterfield, K. D, and Skaggs, B.C (1998). Relationship and unethical behaviour; A social network perspective. Academy of Management Review,23,14-31.

[22]. Brenner H. (2002) Long-term survival rates of cancer patients achieved by the end of the 20th century: a period analysis. Lancet, 360, 1131-1135.

[23]. Broderick, C. B. (1993). Understanding family processes: Basics of family systems theory. Newbury Park, CA: Sage.

[24]. Brooks - Gunn, J., and Reiter, E. O. (1990). The role of pubertal processes: In S. S. Feldman and G. R. Elliot (Eds.), at the threshold: the developing adolescent, Cambridge, M. A: Harvard University Press.

[25]. Buss, D. M. (1996). Social adaptation and five major factors of personality: In J. S. Wiggins (Eds.), the five factors model of personality: Theoretical perspectives (pp. 180 - 207) New York Guilford.

[26]. Byrne, A., \& Byrne, D. G. (1993). The effect of exercise on depression, anxiety, and other mood states: A review. Journal of Psychosomatic Research, 37, $565 Y 574$.

[27]. Capio D, Pachecho F, Flores M, Canales L, (2000). Quality of life in breast cancer survivors. Cancer Practice Guide, 10, 85-93.

[28]. Carlson, L. E., Bultz, B. D., Speca, M., \& St. Pierre, M. (2000). Partners of cancer patients: Part I. Impact, adjustment and coping across the illness trajectory. Journal of Psychosocial Oncology, 18, 39 Y63.

[29]. Cattel, R. B. (1990). Advances in Caticllian personality theory: In L. A. Pervin (Ed) Handbook of personality: The organization and research (pp. 101 -110) New York: Guildford.

[30]. Coebergh JWW, Janssen-Heijnen MLG, Louwman WJ, (1999) Cancer incidence and survival in the South of the Netherlands, 1955-1999

[31]. Colbert, A. E, Mount, M. K., Harter, J. K. Witt, L. A. \& Barrick, M.R. (2004) interactive effects of personality and perceptions of the work situation on workplace deviance. Journal of applied psychology 89, 599609.

[32]. Coleman MP, Gatta G, Verdecchia A, (2003). EUROCARE-3summary: cancer survival in Europe at the end of the 20th century.

[33]. Costa PT Jr, McCrae RR (1980) Influence of extraversion and neuroticism on subjective well-being: happy and unhappy people. Journal Personality Psychology 38: 668-678.

[34]. Costa, P. T. Jr McCrae, R. R. and Holland, N. (1984). The NEO/FFT Manual supplement: Odessa, FL Psychological assessment resource.

[35]. Costa, P. T., Jr., \& McCrae, R. R. (1992). Normal personality assessment in clinical practice: The NEO personality inventory. Psychological Assessment, 4, 5- 13

[36]. Cotterell, J. L. (1992). The relation of attachments and supports to adolescent well-being and school adjustment: Journal of Adolescent Research (1), 28-42.

[37]. Courneya, K. S. (2003). Exercise in cancer survivors: An over view of research. Medicine and Science in Sports and Exercise, 35,1846Y1852.

[38]. Deyo D, Dichr J. \& Patrick M. (2001). State Anxiety and Higher - order factors of the Big Five Journal of personality and social psychology, 73, 1246-1256.

[39]. Donnelly, J. M., Kornblith, A. B., Fleishman, S., Zuckerman, E., Raptis, G., Hudis, C. A., et al. (2000). A pilot study o finter personal psychotherapy by telephone with cancer patients and their partners. Psycho-Oncology, 9, $44 Y 56$.

[40]. Dorval M, Maunsell E, Deschenes L, (1998). Long-term quality of life after breast cancer: comparison of 8year survivors with population controls. Journal of Clinical Oncology, 16, 487-494. 
[41]. Engel J, Kerr J, Schlesinger-Raab A, Eckel R, Sauer H (2003). Predictors of quality of life of breast cancer patients. Acta Oncology 42: 710-718.

[42]. Ernst, E. (1998). Complementary therapies for depression. Archives of General Psychiatry, 55, 1026 Y1032. [43]. Ferrell BR, Grant MM, and Funk BM, (1998). Quality of life in breast cancer survivors: implications for developing support services. Oncology Nursing Forum, 25, 887-95.

[44]. Ferrell, B., Grant, M., Funk, B., Otis-Green, S., \& Garcia, N.(1997a). Quality of life in breast cancer: Part I. Physical and social well-being. Cancer Nursing, 20, $398 Y 408$.

[45]. Ferrell, B., Grant, M., Funk, B., Otis-Green, S., \& Garcia, N. (1997). Quality of life in breast cancer: Part II. Psychological and spiritual well-being. Cancer Nursing, 21, Accessed October 12, 2006.

[46]. Ganz PA, Desmond KA, Leedham B, (2002). Quality of life in long term, disease-free survivors of breast cancer: a follow-up study. Journal National Cancer Institution 2002, 94, 39-49.

[47]. Ganz PA. (2003) Why and how to study the fate of cancer survivors: observations from the clinic and research laboratory. European Journal Cancer 39, 2136-2141.

[48]. Garavito A (2001); Gomez Villegas De Posada, Barrera H and Cruiz Y, (2007)). What does the WHOQOLBref measure? Measurement overlap between quality of life and depressive symptomatology in chronic somatoform pain disorder. Soc Psychiatry Psychiatr Epidemiol; 41:81-86.

[49]. Giese-Davis \& Spiegel C, (2003). What variables predict generic and health-related quality of life in a sample of Brazilian women experiencing breast cancer? Cancer Bulletin; 22:1.

[50]. Giese-Davis, J., \& Spiegel, D. (2003). Emotional expression and cancer progression. In R. J. Davidson, K. R. Scherer, \& H. H.

[51]. Godwin D, Altman DG, Bland JM. The normal distribution. (2002); The Women personality Complexity. Journal of Human Personality vol, 23. 234-254.

[52]. Goldsmith (Eds.), Handbook of affective disorders (pp.1053Y1082). New York: Oxford University Press.

[53]. Greenberg, D. B. (2004). Barriers to treatment of depression in cancer patients. Journal of the National Cancer Institute: Monographs, 32, 127 Y135.

[54]. Greenler RT, Murray T, Bolden S, Wingo PA (2000) Cancer statistics 2000. CA Cancer Journal Clinical 50: 7-33.

[55]. Han, W. T., Collie, K., Koopman, C., Azarow, J., Classen, C.,

[56]. Hankin C. \& Abramson B. (2001). Ethnicity, nationality and gender: A cross-cultural comparison of business depression. The International Journal of Human Resource Management, 7(4), 866-877

[57]. Hann, D., Winter, K., \& Jacobsen, P. (1999). Measurement of depression in cancer patients: Evaluation of the Center for Epidemiological studies depression scale (CES-D). Journal of Psychosomatic Research, 46, $437 Y 443$.

[58]. Härtl K, Janni W, Kästner R, Sommer H, Strobl B, et al. (2003) Impact of medical and demographic factors on long-term quality of life and body image of breast cancer patients. Annual paper of Oncology 14: 1064-1071. Society AC. Cancer facts and figures-2000. Atlanta; 2000.

[59]. Hersen, M., Bellack, A. S., \& Himmelhoch, J. M. (1981). Social skills training compared with pharmacotherapy and psychotherapy in treatment of unipolar depression. American Journal of Psychiatry, 138, $1562 Y 1567$.

[60]. Katz, M. R., Kopek, N., Waldron, J., Devins, G. M., \&Tomlinson, G. (2004). Screening for depression in head andneck cancer. Psycho-Oncology, 13, 269 Y280.

[61]. Klerman, G. L., \& Weissman, M. M. (1993). Applications of interpersonal psychotherapy. Washington, DC: American Psychiatric Press.

[62]. Kornblith AB, Herndon 2nd JE, Weiss RB, (2003) et al. Long-term adjustment of survivors of early-stage breast carcinoma, 20 years after adjuvant chemotherapy. Journal of Clinical, 98, 679-689.

[63]. Kuijpers T, Van Der Windt DA, Van Der Heijden GJ, (2004). Systematic review of prognostic cohort studies on shoulder disorders. Pain Bulletin, 109, 420-431.

[64]. Lawlor, D. A., \& Hopker, S. W. (2001). The effectiveness of exercise as an intervention in the management of depression: Systematic review and meta-regression analysis of randomized controlled trials. British Medical Journal, 322, $763 Y 767$.

[65]. Maggard, M. A., Thompson, J. E., \& Ko, C. Y. (2003). Why do breast cancer mortality rates vary across states? The American Surgeon, 69, 59 Y62.

[66]. Malik S, Coulson N. The male experience of cancer: a thematic analysis of an online cancer support group bulletin board. J Reprod Infant Psychol 2008; 6:18-30. 
DOI: $10.21522 . / T I J P Y .2016 . S E .19 .01 . A r t 001$

ISSN: $2518-8852$

[67]. Manne, S., Ostroff, J., Sherman, J., Glassman, M., Ross, S., Goldstein, L., et al. (2003). Buffering effects of family and friend support on associations between partners' unsupportive behaviors and coping among women with breast cancer. Journal of Social and Personal Relationships, 20, 771 Y792.

[68]. Manne, S., Sherman, M., Ross, S., Ostroff, J., Heyman, R. E., \&Fox, K. (2004). Couples’ support-related communication, psychological distress, and relationship satisfaction among women with early stage breast cancer. Journal of Consulting and Clinical Psychology, 72, $660 Y 670$.

[69]. Meyer, T. J., \& Marks, M. M. (1995). Effects of psychosocial interventions with adult cancer patients: A meta-analysis of randomized experiments. Health Psychology, 14, 101 Y108.

[70]. Mock, V., Pickett, M., Ropka, M. E., Muscari Lin, E., Stewart, K. J., Rhodes, V. A., et al. (2001). Fatigue and quality of life outcomes of exercise during cancer treatment. Cancer treatment Practice Guide, 9, 119 Y127.

[71]. Montazeri A. Health-related quality of life in breast cancer patients: a bibliographic review of the literature from 1974 to 2007. J Exp Clin Cancer Res 2008; 27:32.

[72]. Morrow, G. R., et al. (2005). Breast cancer and problems with medical interactions: Relationships with traumatic stress, emotional self-efficacy, and social support. Psycho-Oncology, 14,318Y330.

[73]. Nancy R, Lawton, M. \& Pikson P. (2005). Measures of quality of life and subjective well-being. Generations, 21(1), 45-47.

[74]. Radloff, L. S. (1977). The CES-D scale: A self-report depression scale for research in the general population. Applied Psychological Measurement, 1, 385 Y401.

[75]. Rehse, B., \& Pukrop, R. (2003). Effects of psychosocial interventions on quality of life in adult cancer patients: Meta-analysis of 37 published controlled outcome studies. Patient Education and Counseling, 50, $179 Y 186$.

[76]. Rodriguez L, Aaronson (1998). Quality of life: what is it? How should it be measured? Journal of Oncology; 2:69-74.

[77]. Ruskin, P. E., Silver-Ayalian, M., Kling, M. A., Reed, S. A., Bradham, D. D., Hebel, J. R., et al. (2004). Treatment for cancer patients. Unpublished article.

[78]. Scholten-Peeters GG, Verhagen AP, Bekkering GE, (2003). Prognostic factors of whiplash-associated disorders: a systematic review of prospective cohort studies. Pain Bulletin, 104, 303-322.

[79]. Schou W, Ekeberg Fleck M, Ruland H, Sandvik S \& Karensen P. (2004). Investigating psychological predictors of health-related quality of life in cancer patients:a systematic review. Journal of Psychosom Obstet Gynaecol 2010a; 31:101-110.

[80]. Simpson JS, Carlson LE, Trew ME.(2003) Effect of group therapy for breast cancer on healthcare utilization. Cancer Practice, 9, 19-26.

[81]. Stark D, Kiely M, Smith A, Velikova G, House A (2002) Anxiety disorders in cancer patients: their nature, associations, and relation to quality of life. Journal Clinical Oncology 20: 3137-3146.

[82]. Theofilou P (2010) Assessment of health - related quality of life: The contribution of social sciences. EJournal of Study and Technology 2: 19-32.

[83]. Theofilou P (2010) Quality of life in the field of health: meaning and assessment. E-Journal of Study and Technology 4: 43-53.

[84]. Theofilou P (2011) Sexual functioning in Chronic Kidney Disease: The association with depression and anxiety. Hemodial International E-publication [ ahead of print].

[85]. Theofilou P (2011) Why is it important to assess health - related quality of life? Journal Palliative Care Medicine 1: 1-2.

[86]. Theofilou P (2012) Major depression in women diagnosed with breast cancer. Journal Intern Med [Epub ahead of print].

[87]. Theofilou P (2012) Quality of life outcomes in patients with breast cancer. Oncology Reviews [Epub ahead of print].

[88]. Theofilou P (2012) The relationship of social support to mental health and locus of control. Journal of Renal Nursing [Epub ahead of print].

[89]. Tomich PL, Helgeson VS.(2002) Five years later: a cross-sectional comparison of breast cancer survivors with healthy women. Psycho oncology, 11, 154-169.

[90]. Visser O, Coebergh JWW, van Dijck JAAM, Seisling S (2001) Incidence of cancer in the Netherlands 1998. Tenth report of the Netherlands Cancer Registry.

[91]. Weitzner MA, Meyers CA, Stuebing KK, (1997). Relationship between quality of life and mood in longterm survivors of breast cancer treated with mastectomy. Support Care Cancer, 241-248. 
[92]. Wilhelm B J, \& Roy Takefman (2002); The Fertility, Depressive symptomatology and Anxiety Tool: Development and general psychometric properties. Journal Clinical; in press.

[93]. World Health Organization (2009). WHOQOL Study Protocol. WHO (MNH/PSF/93.9).

[94]. World Health Organization. (1991). Report of the WHO Meeting on the Assessment of Quality of Life in Health Care. Geneva: WHO (MNH/PSF/91.4)

[95]. World Health Organization. (1992a). Report of Meeting on Quality of Life. Geneva: WHO (MNH/PSF/92.2). [96]. World Health Organization. (1992b). Report of the Meeting of Investigators on Quality of Life. Geneva: WHO (MNH/PSF/92.6)

[97]. World Health Organization. (1992c). Report of the Meeting for the Training of WHOQOL Focus Group Moderators. Geneva: WHO (MNH/PSF/92.9)

[98]. World Health Organization. (1993a). Report of WHOQOL Focus Group Work. Geneva: WHO (MNH/PSF/93.4).

[99]. Zigmond Levas, Zainath, J., \& Noreau, L. (2004). Review of HADS instrument psychometric properties associated with quality of life of older adults with physical disabilities? Disability \& Rehabilitation, 26(20), 12061213. 


\section{Texila American University}

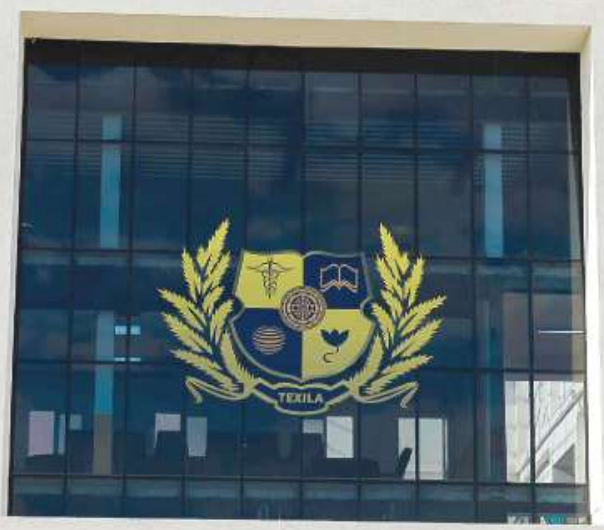

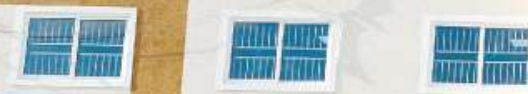

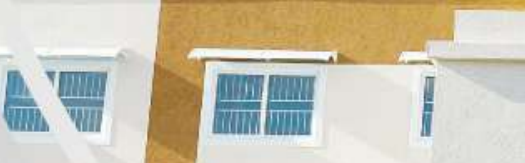

=

An.
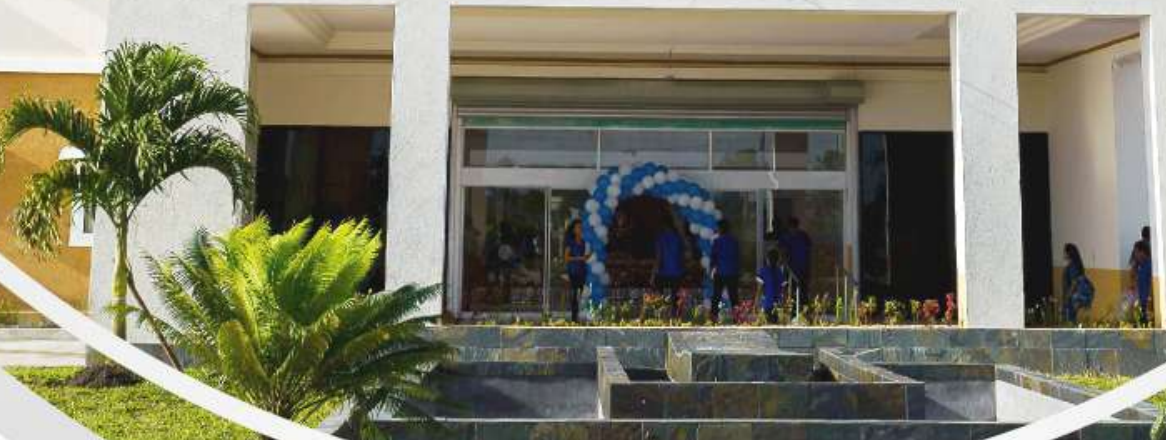

\section{(1) $\begin{array}{ll}\text { TEXILA } \\ \text { INTERNATIONAL }\end{array}$ e-CONFERENCE}

Texila American University, Lot 2442, Plantation Providence, East Bank Demerara(Ebd), Gayana, South America.

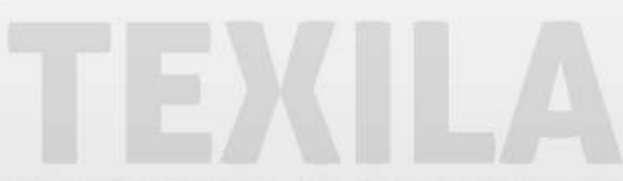

INTERNATIONAL JOURNAL OF

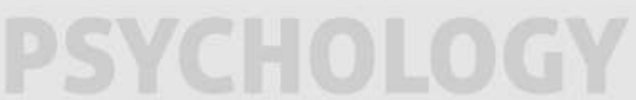

\section{GLOBAL OFFICE}

Texila Educational \& Management Services (P) Ltd Module 310, lii Floor, Tidel Park Aerodrome Post, Coimbatore-641014 E-mail : Iseconference@tau.edu.gy 